\title{
Reflection of Strategic Behaviors in Scenario Planning
}

\author{
Assistant Prof . Hussein Waleed Hussein, Assistant Prof Dr. Abdulnaser Alag Hafedh \\ Ministry of Higher Education and Scientific Research
}

DOI: $10.37648 /$ ijrssh.v10i04.013

Received:14 $4^{\text {th }}$ September, 2020; Accepted:14 ${ }^{\text {th }}$ October, 2020; Published:15th October, 2020

\begin{abstract}
The research aims to discuss how to employ the strategic behaviors of (participatory behavior, transformational behavior, procedural behavior) in planning scenarios through its stages represented in (defining basic factors, predicting future scenarios, forming scenarios, and detailing scenarios), as the research problem indicated the existence of Weakness in how strategic behaviors are used in scenarios planning, and therefore the importance of research has been to try to enhance knowledge in this field to suggest solutions to address the problem related to it. In order to achieve the goals of the research, the descriptive approach was adopted, as a questionnaire was designed based on a number of indicators and ready criteria, which were distributed on the strength of (127) individuals from the Asiacell Communications Company, and after data processing using the program (SPSS.V21), was Reaching several results that confirmed the importance of the role that strategic behaviors play in scenarios planning, and accordingly it was recommended that a mechanism be established to enhance coordination between senior management and human resources in order to unify their strategic behaviors, and to invest their results in providing the inputs on which to base scenarios planning.
\end{abstract}

Key words: strategic behaviors, scenario planning, environmental factors, the future, organizational goals.

\section{FIRST : INTRODUCTION}

Strategic behaviors represent one of the important topics in the field of strategic management and organizational behavior at the same time, as it focuses on the nature of the behaviors adopted by the top management in dealing with its human resources inside the organization, and with other parties outside it, as well as the fact that these behaviors represent the engine and guide for many Strategic decisions that are taken to deal with future issues, which enable it to stay and continue working. On the other hand, scenario planning is an important tool for envisioning the future in various situations, on the basis of which strategies are built that help the organization prepare to deal with the various situations and fields that it may encounter. Hence, the idea of this research emerged in an attempt to present a modest study that explores the importance of employing strategic behaviors in the effectiveness of scenario planning, focusing on its various stages. In order to achieve this idea, this research included four sections, the first was devoted to discussing the most important methodological foundations that outline the general lines of the research, while the second topic discussed the theoretical and cognitive pillars of the researched variables, and the third chapter came to explain the most important applied results that were reached within the framework of answers Finally, the fourth chapter summarized the conclusions that were drawn within the framework of the interpreted results, 
(IJRSSH) 2020, Vol. No. 10, Issue No. IV, Oct-Dec

and the recommendations that were proposed to complete the scientific journey.

\section{SECOND: RESEARCH METHODOLOGY :}

This paragraph summarizes the most important methodological foundations upon which the research is based, which represent the broad outlines in its implementation in its various parts, with a discussion of some previous intellectual efforts to deepen awareness of the importance of the topic and then build a correct beginning for it, as in the following paragraphs:

1. Research problem : Strategic behaviors affect human resources working at different organizational levels, but they reflect the orientations of the higher leadership, and affect the nature of the strategic directions of their organization and all parties related to it, whether inside or outside it, and the scenarios also cover all possibilities that may face the organization when implementing its strategy in the future. Therefore, the failure to employ strategic behaviors in enhancing the effectiveness of scenario planning is a big problem, which organizations must address and address, and this is what the researcher touched in the researched organization, and the researcher's problem can be strengthened by raising some questions, most notably the following:

- What is the reality of strategic behaviors within the researched organization?

- What is the reality of the effectiveness of scenario planning within the research organization?

- What is the reality of the nature of the relationship between strategic behaviors and the effectiveness of scenario planning in terms of
e-ISSN: 2249-4642, p-ISSN: 2454-4671

coherence and influence within the researched organization?

2. Research Importance : The importance of the research is summarized in two aspects, the first seeks to review a set of literature on the variables researched and to identify the most important philosophical foundations that were addressed by researchers and interested people, in order to provide a modest theoretical addition that reflects the most important cognitive pillars of strategic behaviors and planning scenarios. As for the second aspect, it focuses on using a set of indicators and standards that have already been tested, and trying to benefit from them in diagnosing the problems facing the researched organization to the extent that it relates to research variables, and then generating solutions and treatments to overcome these problems.

3. Research objectives : The current research seeks to achieve three main objectives, namely:

- Identify the reality of strategic behaviors and plan scenarios within the research organization.

- Identify the nature of the interdependence and influence relationships between strategic behaviors and planning scenarios within the researched organization.

- Draw some conclusions and suggest some recommendations that would deepen knowledge of strategic behaviors and planning scenarios.

4. The hypothetical model : The hypothetical model of the research summarizes its main idea of employing strategic behaviors in planning scenarios for the researched organization, within the framework of the interdependence and influence relationships between them, and as shown in Figure (1): 


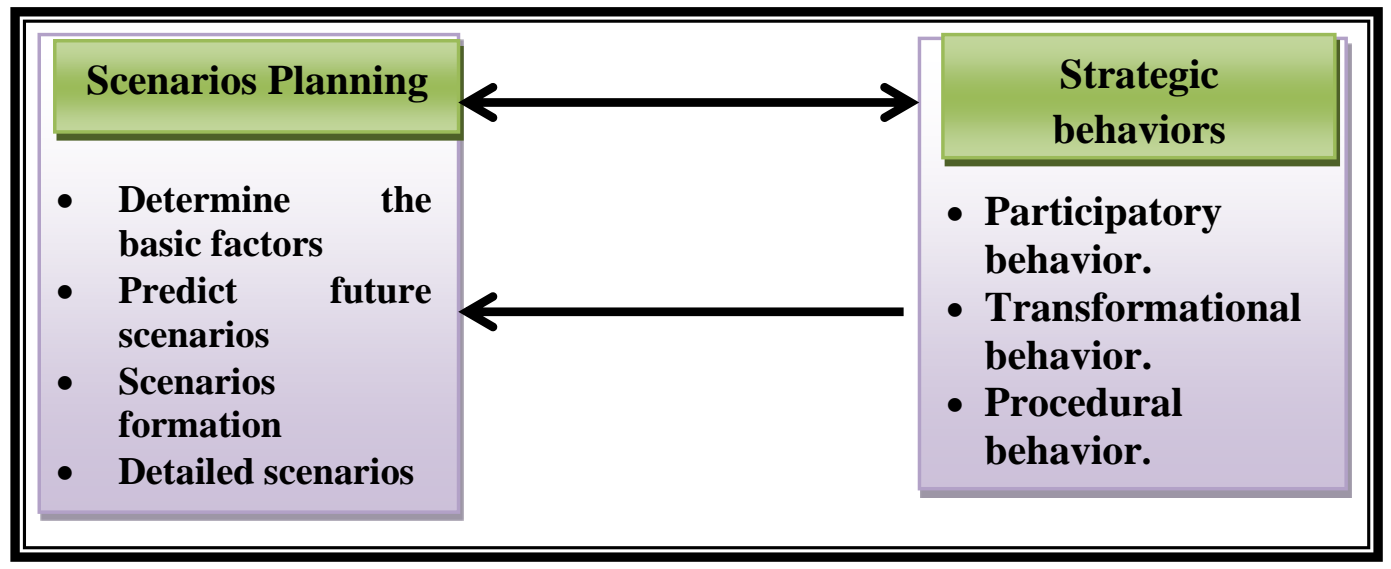

Figure (1) hypothesis research outline

5. Research Assumes : Based on the intellectual premise of the hypothetical research model, two hypotheses were formulated for the research, which the researcher tries to prove the validity of one of them at the expense of the second:

- The first hypothesis: (There is a significant and statistical correlation and influence between strategic behaviors and planning scenarios within the researched organization).

- The second hypothesis (there is no significant and statistical correlation and impact relationship between strategic behaviors and planning scenarios within the researched organization).

6. Research tools : The descriptive approach was adopted in applying the research because it is aligned with its goals and directions, as the researcher collected data through the use of a questionnaire, which was prepared according to some ready-made measures, as he adopted the model adopted in the study (Mirabeau \& Maguire, 2014) to design paragraphs of strategic behaviors, as for the paragraphs Scenarios planning have been prepared according to the ideas of (Bouhalleb \& Smida, 2019), and the questionnaire was subjected to validity and stability tests to suit the main purpose of this research, as it was presented to a number of specialists to identify its validity and the extent of compatibility between its paragraphs and dimensions, and it achieved an agreement percentage of ( $91 \%)$, which is a good percentage, as for the stability of the questionnaire, it was ascertained by distributing the questionnaire twice to the same sample within two periods of time separated by (14) days, and after processing the data, it achieved a stability rate of $(87 \%)$, which is a very good percentage. And it confirms the ability of the questionnaire to give the same results if it was distributed to the same sample in separate periods. The researcher also conducted a test of the normal distribution of the data to ensure the possibility of using measures of central tendency in its analysis, and the results were more than (0.05), which confirms the data follow the normal distribution, as for the existence of the scale and its conformity with the research model and its hypotheses, they were tested using confirmatory and exploratory factor analysis., As most of the results were greater than the standard ratio of (1.96), and these results confirm the ability of the scale to collect data that are compatible with the research objectives. The researcher has relied on a set of statistical tools available within the programs (SPSS.V21) \& (AMOS) in data processing, which was referred to in the third topic and as much as it relates to the objectives that the research seeks to achieve, and the hypotheses that it intends to test.

7. The research community and its sample : The telecommunications sector was chosen as a field of application, as it represented the research community at Asiacell Communications Company, and the main reason for choosing it is that it works in a field characterized by successive and accelerating developments, as well as being operating in a dynamic environment due to the exceptional circumstances that the country is going through, and this confirms the importance of employing its 
strategic behaviors in planning The scenarios that it adopts to deal with different situations and fields that you face in the future. As for the research sample, it consisted of (127) individuals from the employees of the Asiacell company, and it constitutes more than $10 \%$ of the employees of the company, so it is statistically acceptable, and is able to represent the society in the best way. Among the most prominent characteristics of the researched sample is that the percentage of males and females is higher than the percentage of males, as it reached (64\%), and that the largest percentage of the researched sample had a service of more than (10) years, as their percentage reached $(78 \%)$, and that all the members of the studied sample are Of the holders of a university degree, i.e. $(100 \%)$

\section{THIRD: A REVIEW OF THE THEORETICAL LITERATURE}

This topic is devoted to discussing the most important intellectual and philosophical foundations that researchers dealt with in studying the researched variables, in order to rely on them in formulating the theoretical aspect of this research, and as in the following paragraphs:

\section{Strategic Behaviors}

Strategic behaviors represent one of the concepts of great importance because it combines two important areas of management, namely organizational behavior and strategic management. Therefore, the approaches to which researchers relied on defining strategic behaviors varied. The researcher (Burgelman, 1983: 62) confirmed that the strategic behavior emerged as a result of the organizations 'reliance on a set of measures to enhance their independence in implementing their own strategy and adapting to their external environment. The strategic behavior was defined as: "the behavioral responses that human resources take towards the changes and developments that occur in their environment, and which are based on them in making strategic decisions affecting the organization." The same trend was defined as: "The behaviors adopted by senior management in order to enhance Social domination of the human resources that they deal with within the organization, in order to achieve coordination and synergy between them, and then achieve the goals of their organization "(Olthof el at,
2011: 343). It was also defined as: "Behaviors that affect human resources decisions after several ways by employing the information available to them to achieve their personal predictions and in line with their preferences and expectations", that is, behaviors that affect managers' predictions about the nature of the financial results that the organization can achieve during The coming future periods as a result of adopting specific strategies (Liu \& Natarajan, 2012: 2124). From a purely strategic point of view, strategic behaviors were defined as: "The behaviors that seek to achieve integration between the strategy of the main organization and all the sub-strategies that stem from it in order to achieve complementarity in achieving them" (Mirabeau \& Maguire, 2014: 1205). According to the introduction of value addition, it was defined as: "The valuable behaviors that managers adopt when implementing their strategic tasks within their organization, and they are based on building their expectations and predictions on the mechanism of deepening the interconnection between their orientations and the directions of their strategic organization, to achieve integration and unify efforts to achieve them" (Shi \& Lian, 2015: 2). Accordingly, strategic behaviors are represented by: "A set of behaviors adopted by senior management to enhance interactions between all parties that deal with the organization, and then achieve the economic value added to them by investing the results of this interaction" (Crawford, 2016: 2), and the researcher can define the behaviors The strategy, from his point of view, is: "A set of behaviors adopted by senior management to enhance the degree of engagement and cooperation with human resources at various organizational levels, in order to share responsibility and transfer part of it to them, within the framework of a set of procedures and policies that are adopted to achieve the strategy of the main organization". With regard to the importance of strategic behavior, it has been pointed out that its influence extends to all parties that deal with the organization, whether they are inside or outside it, to ensure that there is harmony between their interests and invest their efforts and support in achieving the strategic directions that it seeks, as well as avoiding conflicts that could negatively affect them. (Burks el at, 2009: 7746), through which it is possible to strengthen the mechanisms of teamwork and cooperation within the organization, and then the possibility of benefiting from its synergies in supporting the decisions it makes, specifically the strategic ones (Ben-Porat el at, 2020: 
439). There is a set of strategic behavioral patterns, including: "the defensive pattern that seeks to preserve the current situation, the prospective pattern that searches for new opportunities, the analytical pattern that combines the two previous patterns, and finally the responsive pattern that is subject to all environmental developments". There are three types of strategic behavior that the researcher will try to study in this research, which are: 1- Participatory style: The strategic behavior here focuses on achieving cooperation and coordination between management and human resources at the different organizational levels, by adopting the method of work teams or collective management, in order to exchange opinions and suggestions and take Decisions jointly. 2- Transformational style: This type of behavior depends on ethical standards in managing and directing human resources, by motivating them to deal with challenges and accomplish works of high value to them and their organization. 3- Procedural style: Behavior depends on this pattern on a set of rules and procedures in carrying out tasks and duties within the organization, taking into account the terms of flexibility and focus in it (Liu \& Natarajan, 2012).

\section{Planning Scenarios}

The contemporary dynamic environment has created great challenges for organizations that must be dealt with, if they want to stay and continue to work within their borders, and in order to achieve this they must predict all future situations that they may be exposed to, and here the function of scenario planning to deal with these future perceptions emerges. The historical roots of scenario planning go back to military strategic studies, especially in the mid-nineteenth century with studies related to nuclear wars under the title (thinking about what cannot be thought). The scenario was also defined as: "Stories with different structures that show how the future is envisioned and developed for the organization. As for scenario planning, it is an innovative approach that reflects the ability of senior management to develop and maintain an integrated view of the future" (Aldabbagh \& Allawzi, $2019: 5$ ). The scenario planning process has been defined by several definitions, including: "A future tool used to analyze the environmental variables facing the organization in the future, to take the necessary measures to deal with them" (Chermack \& Swanson, 2008 : 130), On the other hand, it was defined as: "A series of measures adopted by the organization to deal with future developments, and the uncertainties facing the organization in the long term" (Volkery \& Ribeiro, 2009 : 1199). For the success of scenario planning, two elements are required, namely desirability, meaning compatibility between scenarios and the orientations of all parties involved in its implementation, and credibility, meaning that the scenario is built by specialists in order to ensure its success in the case of implementation, in addition to being unique and distinct, and can be relied upon in making decisions by the organization For being realistic. Focusing on the two sides of opportunities and challenges, the scenario planning process was defined as: "a mechanism to reveal the most important opportunities and challenges facing the organization in the future, and then formulate the necessary strategies to deal with them" (Khosravi \& Jha-Thakur, $2018: 2$ ). As for the approach to decision-making and focusing on the areas of investment facing the organization in its environment, it has been defined as: "The integrated approach that managers rely on in making strategic decisions in the context of environmental uncertainty to rationalize their investment fields" (Hanafizadeh el at, 2019 : 24). In line with the previous idea, the scenario planning process was defined as: "the logical approach adopted by the organization to deal with the dynamic developments it faces in the future" (Bowman \& MacKay, 2020: 1). Accordingly, scenario planning can be defined hypothetically by the researcher and based on the cognitive foundations previously discussed as: "The process by which the most important basic factors for building future visions facing the organization are determined and the scenarios are formulated to deal with them, and they are detailed into a set of applicable activities and tasks". Scenario planning is extremely important in contemporary organizations, and through scenario planning it is possible to balance the different time periods that the organization requires to achieve its strategy, as well as its importance in determining the priority of the activities that it undertakes to do so (Bowman \& MacKay, 2020: 3). It also contributes to providing appropriate inputs that can be relied upon in making strategic decisions to implement plans and translating them into tangible results on the ground, as well as the importance of enhancing interaction and cooperation between stakeholders in order to provide this information or input, that is, it is a way to understand the future in its various cases and Then stimulate the cases of innovation and creativity of the organization to direct its 
strategic efforts in its direction (Aldabbagh \& Allawzi, 2019 : 6). Scenario planning has also been referred to as the most important tools that are adopted to enhance the strategic flexibility with which the organization deals with contemporary developments, and thus reduce the levels of complexity that it may face in the future. There is a set of steps that must be implemented for the success of scenario planning, which the researcher will try to study in the practical side of his research, namely: 1Determining the basic factors: In this stage, the most important factors affecting the success of the scenarios are determined by carrying out diagnostic and analytical processes to identify their causes. 2- Predicting future scenarios: In this stage, the future horizons of the scenarios and the most important changes that may occur during these periods are determined. 3- Formation of scenarios: that is, representing the future with identical and appropriate cases of the factors and predictions that were previously identified. 4- Scenarios detailing: that is, determining the strength of the scenario and the most important consequences of it, along with identifying the nature of the opportunities and challenges accompanying it, and the most important factors that must be provided for its success (Bouhalleb \& Smida, 2019 : 3).

\section{The Theoretical Relationship Between The Studied Variables}

Through strategic behavior, it is possible to integrate the areas of change that the organization seeks in the future, with the scenarios that it sets to deal with, and accordingly it forms the point from which scenario planning starts (Chermack \& Swanson, 2008 : 135). The strategic behavior also plays an important role in dealing with emergency situations, and employing them within the scenarios adopted by the organization in the long term (Volkery \& Ribeiro, 2009 : 1202). Strategic behaviors also play their important role in the processes of sensing and seizing and reconfiguring the resources and capabilities of the organization, in order to enhance its flexibility and ability to deal with its environment and plan future scenarios to deal with it (Bodwell \& Chermack, 2010 : 199). The study that was conducted from (Aldabbagh \& Allawzi, 2019 : 4) That the strategic behavior contributes to the perception of prospects of opportunities and areas in which the organization can invest in the future to compete and survive, and then through this behavior can improve cognitive attempts to plan future scenarios. Accordingly, the philosophical foundations became clear on which the researcher relied in formulating the research hypotheses.

\section{FOURTH: ANALYZING DATA AND DISCUSSING RESULTS}

Diagnosis of the reality and importance of the variables discussed The researcher tries to ensure the existence of the researched variables within the organization in the field of application within the framework of the results produced by the statistical tools listed in Table (1), and the following is an explanation of them:

Table (1) Diagnosis of the reality and importance of the studied variables

\begin{tabular}{|c|c|c|c|c|c|c|}
\hline $\mathbf{T}$ & Variables & $\begin{array}{l}\text { Agreement } \\
\text { percentage }\end{array}$ & $\begin{array}{l}\text { Arithmetic } \\
\text { mean }\end{array}$ & $\begin{array}{l}\text { standard } \\
\text { deviation }\end{array}$ & $\begin{array}{l}\text { Coefficient } \\
\text { of variation }\end{array}$ & $\begin{array}{l}\text { Relative } \\
\text { importance }\end{array}$ \\
\hline 1 & Participatory behavior & $\% 990$ & 4.3 & 0.57 & 0.13 & 1 \\
\hline 2 & $\begin{array}{l}\text { Transformational } \\
\text { behavior }\end{array}$ & $\% 87$ & 3.6 & 0.68 & 0.19 & 3 \\
\hline 3 & Procedural behavior & $\% 89$ & 3.9 & 0.64 & 0.16 & 2 \\
\hline \multicolumn{2}{|c|}{ Strategic behaviors } & $\% 89$ & 3.9 & 0.63 & 0.16 & 1 \\
\hline 4 & $\begin{array}{l}\text { Determine the basic } \\
\text { factors }\end{array}$ & $\% 83$ & 3.2 & 0.65 & 0.20 & 3 \\
\hline 5 & Predict future scenarios & $\% 85$ & 3.5 & 0.63 & 0.18 & 2 \\
\hline 6 & Scenarios formation & $\% 91$ & 4.2 & 0.54 & 0.15 & 1 \\
\hline 7 & Detailed scenarios & $\% 81$ & 3.1 & 0.71 & 0.23 & 4 \\
\hline \multicolumn{2}{|c|}{ Scenarios Planning } & $\% 85$ & 3.5 & 0.63 & 0.18 & 2 \\
\hline
\end{tabular}

Source: Prepared by the researchers, 2020. 
1. It is clear from Table (1) that the strategic behavior variable achieved an agreement rate $(89 \%)$, which is a very good percentage and confirms the prevalence of strategic behaviors within the research organization, when making decisions and implementing activities and tasks in coordination between senior management and human resources working at different levels, in addition to The fact that this percentage is higher than the standard percentage of the agreement. The value of the arithmetic mean coincided with the aforementioned results, as it reached (3.9), which confirms the existence of strategic behaviors at a high level within the researched organization, and is higher than the hypothetical mean of (3), while the value of the standard deviation confirms the existence of a statistically high harmony between the sample. The researcher discussed the direction of this variable, as its value reached (0.63), and the value of the difference coefficient confirmed the decrease in the dispersion between them, as its value reached (0.16). The strategic behaviors variable ranked first in terms of its relative importance compared to the scenario planning variable. As for the relative importance of the dimensions of the strategic behavioral variable, the participatory behavior ranked first over the other behaviors with an arithmetic mean (4.3), while the procedural behaviors ranked second with an arithmetic mean (3.9), and finally the transformative behaviors ranked last with an arithmetic mean (3.6).

2. We note in Table (1) that the percentage of agreement regarding the scenario planning variable reached $(85 \%)$, which is a very good percentage, and confirms the interest of the researched organization in planning scenarios when dealing with future cases, by drawing its own perceptions and determining the most important strategies that can be adopted to deal With it, these results came in line with the value of the arithmetic mean of this variable, as it reached (3.5), which is higher than the hypothetical mean, and confirms the existence of planning scenarios at a high level within the researched organization, while the value of the standard deviation was (0.63), which confirms the high harmony between the studied sample The direction of the paragraphs of this variable, as the value of the difference coefficient confirmed the lack of dispersion between these answers, as its value reached (0.18), and with regard to the relative importance of the total variable planning scenarios, it came second after the variable of strategic behaviors. As for the sub-dimensions of scenario planning, it was advanced after the formation of the scenarios in the first rank in relation to the relative importance with an arithmetic mean (4.2). As for predicting future scenarios, it came in second place with an arithmetic mean (3.5), while the main factors came in third place with an arithmetic mean (3.2). Finally, after detailing the scenarios, it came last, as its mean value reached (3.1).

\section{Choosing research hypotheses}

This paragraph is devoted to identifying the correlation and influence relationships between the researched variables, and then testing the validity of one of the research hypotheses for acceptance and rejection of the other, regarding the results of correlation, it can be explained in Table (2):

Table (2) results of correlation relationships

\begin{tabular}{|l||l||l||l||l||l||}
\hline \hline & $\begin{array}{l}\text { Determine } \\
\text { the basic } \\
\text { factors }\end{array}$ & $\begin{array}{l}\text { Predict } \\
\text { future } \\
\text { scenarios }\end{array}$ & $\begin{array}{l}\text { Scenarios } \\
\text { formation }\end{array}$ & $\begin{array}{l}\text { Detailed } \\
\text { scenarios }\end{array}$ & $\begin{array}{l}\text { Scenarios } \\
\text { Planning }\end{array}$ \\
\hline \hline Participatory behavior & $* * 0.64$ & $* * 0.52$ & $* * 0.67$ & $* * 0.49$ & $* * 0.58$ \\
\hline \hline Transformational behavior & $* * \mathbf{0 . 6 2}$ & $* * \mathbf{0 . 5 7}$ & $* * 0.59$ & $* * \mathbf{0 . 6 1}$ & $* * \mathbf{0 . 6 0}$ \\
\hline \hline Procedural behavior & $* * \mathbf{0 . 5 9}$ & $* * \mathbf{0 . 6 1}$ & $* * \mathbf{0 . 5 3}$ & $* * \mathbf{0 . 6 4}$ & $* * \mathbf{0 . 5 9}$ \\
\hline \hline Strategic behaviors & $* * \mathbf{0 . 6 2}$ & $* * \mathbf{0 . 5 7}$ & $* * \mathbf{0 . 6 0}$ & $* * 0.58$ & $* * 0.59$ \\
\hline
\end{tabular}

* Correlation at the level of significance 0.05 .

** Correlation at the level of significance 0.01 .

Source: Prepared by the researchers, 2020. 
It is evident from Table (2) that the strategic behavior variable and its dimensions achieved (25) a moral correlation relationship with the scenario planning variable and their dimensions, and this result confirms the importance of the reciprocal relationship between these two variables, and statistically reflects that there is an overlapping role between them that confirms the importance of employing one of them in the success of the other, whether it is The variable is explanatory or responsive, and the value of the correlation between the total variable of strategic behaviors and the total variable planning scenarios $(0.59 * *)$, which is a strong and positive relationship at the same time, has a significant significance (0.01) and with confidence limits (0.99). As for the results of influence relationships, they can be explained in Table (3):

Table (3) Results of influence relationships

\begin{tabular}{|c|c|c|c|c|c|c|}
\hline & $\mathbf{B}$ & $\mathbf{a}$ & $\mathbf{R}^{2}$ & $\mathbf{F}$ & Moral & $\begin{array}{l}\text { Relative } \\
\text { importance }\end{array}$ \\
\hline Participatory behavior & 0.91 & 0.78 & $\%$ \%34 & 27.32 & 0.001 & \%100 \\
\hline $\begin{array}{l}\text { Transformational } \\
\text { behavior }\end{array}$ & 0.87 & 0.84 & $\% 36$ & 23.65 & 0.001 & $\% 100$ \\
\hline Procedural behavior & 1.06 & 0.68 & $\% 35$ & 29.81 & 0.001 & $\% 100$ \\
\hline Strategic behaviors & 0.95 & 0.77 & \%35 & 26.93 & 0.001 & \%100 \\
\hline
\end{tabular}

Source: Prepared by the researchers, 2020.

It is evident from Table (3) that strategic behaviors affect significantly in planning scenarios within the researched organization, and that the regression model is good to describe the relationship between these two variables, as the calculated value of (f) reached (26.93), which is greater than its tabular value, and the value of $(a)=0.77)$ and it confirms the interest of the researched organization in planning scenarios by (0.77) even if the strategic behaviors within them are equal to zero. As for the value of $(\mathrm{B}=0.95)$, it confirms that changing strategic behaviors one unit will lead to a change in planning scenarios for the researched organization by $(0.95)$. The value of (R2) also confirmed that strategic behaviors explain $(35 \%)$ of the variance in planning scenarios and that $(65 \%)$ of the variance is explained by other factors. After discussing and interpreting the results shown in Tables (2 and 3), the researcher can accept the first hypothesis (there is a significant and statistical correlation and influence between strategic behaviors and planning scenarios within the research organization), and reject the second hypothesis (there is no significant and statistical correlation and influence between strategic behaviors and scenario planning. Within the research organization).

\section{FIFTH: CONCLUSIONS RECOMMENDATIONS}

AND

Conclusions: The most important conclusions that have been drawn are the following:

1. the researched organization invests the strategic behaviors available to it, in implementing its activities and tasks.

2. The researched organization supports the spirit of cooperation and coordination between its administration and its human resources, in order to invest their efforts in the pursuit of the goals it seeks.

3. The researched organization emphasizes the importance of working with transformative behaviors and in a manner that is in line with legal and ethical standards and indicators and with regard to organizing the relationship between its management and its human resources.

4. There is a clear interest on the part of the researched organization in defining the procedural behaviors that human resources adopt in implementing the activities and tasks assigned to them.

5. The researched organization is interested in planning scenarios to deal with developments that it will deal with in the future, by drawing up the policies and procedures necessary to implement its own strategies in the future. 
6. The researched organization is interested in forming scenarios that it adopts in dealing with future situations that it encounters when implementing its projects and strategic plans.

7. The researched organization has the ability to predict all future scenarios that it may encounter in light of its external environment.

8. The researched organization follows up all developments that occur in its internal and external environment, and deals with it as one of the main inputs when planning its own scenarios.

9. The researched organization details the scenarios that it adopts to implement its strategies in the future into a set of activities and implementable tasks.

10. Strategic behaviors play an important role in helping the researched organization to plan scenarios that it adopts in implementing its strategies in the future, particularly through the transformational behavior that achieved the highest correlation with the scenario planning variable.

11. Strategic behaviors contribute in a significant way and affect the planning of scenarios within the researched organization, by employing expertise and previous experiences and self-control when carrying out the planning process.

Recommendations: The most important recommendations that have been suggested are the following:

1. The researcher proposes to develop mechanisms that enhance the investment of strategic behaviors within the researched organization by enhancing interaction and coordination between management and human resources, regardless of their organizational levels.

2. Strengthening teamwork within the organization in question by forming joint committees from its various departments and divisions in order to exchange knowledge between them and achieve intellectual harmony between them.

3. Establishing a series of instructions that define the mechanism for transferring powers and responsibilities from the higher levels to the lower levels, with an emphasis on the need for coordination and adaptation between them.

4. Establishing a set of procedures and policies that define the mechanism for carrying out tasks and duties within the research organization, to ensure control over procedural behaviors related to its human resources.

5. Forming committees of specialists and experts inside and outside the organization in order to enhance the scenario planning processes that it adopts to deal with future developments.

6. The necessity of coordination between the administration and human resources operating within the organization and those available in the external environment, in order to form the main and sub-scenarios that it can adopt in implementing its various projects.

7. Benefiting from the experiences of successful organizations that partner with the researched organization to work within the same sector when predicting future scenarios that occur in its environment.

8. The necessity of updating its databases and information in a manner that is compatible with environmental changes and developments that occur to them, in order to ensure that they are not out of date.

9. Involving human resources within the research organization with a set of training courses that deepen their knowledge and culture about the nature of scenarios that will be adopted in the future.

10. The researcher recommends the researched organization to achieve coordination between senior management and its human resources in various jobs, in order to transfer its strategic behavior to them, and to employ that in providing the inputs that it adopts in formulating its future scenarios.

11. Establishing a group of relationships with academic and development institutions in order to identify the ranges in which strategic behavior can be invested, in order to enhance their ability to plan scenarios that can be adopted in the future. 


\section{RESOURCES :}

1. Bodwell, Wendy \& Chermack, Thomas J. (2010) Organizational ambidexterity: Integrating deliberate and emergent strategy with scenario planning, Technological Forecasting \& Social Change, Vol 77 : pp $193-202$.

2. Ben-Porat, Omer \& Hirsch, Sharon \& Kuchy, Lital \& Elad, Guy \& Reichart, Roi \& Tennenholtz, Moshe (2020) Predicting Strategic Behavior from Free Text, Journal of Artificial Intelligence Research, Vol 68 : pp 413-445.

3. Bouhalleb, Arafet \& Smida, Ali (2019) Exploring the relationship between scenario planning and strategic flexibility and complexity, European journal International Management, Vol 1, No 4 : pp 1-19.

4. Bowman, Gary \& MacKay, R. Bradley (2020) Scenario planning as strategic activity: A practice-orientated Approach, journal of Wiley :pp 1-11.

5. Burgelman, Robert (1983) A Model of the Interaction of Strategic Behavior, Corporate Context, and the Concept of Strategy, Academy of Management Review, Vol 8, No 1 : pp61-70.

6. Burks, Stephen V \& Carpenter, Jeffrey P. \& Goette, Lorenz \& Rustichini, Aldo (2009) Cognitive skills affect economic preferences, strategic behavior, and job attachment, journal Economic sdences , vol 106, No 19 : pp 7745-7750.

7. Chermack, Thomas J. \& Swanson, Richard A. (2015) Scenario Planning: Human Resource Development's Strategic Learning Tool, journal Advances in Developing Human Resources, Vol 10, No 2 : pp 129-146.

8. Crawford, Vincent P. (2016) New Directions for Modelling Strategic Behavior: Game-Theoretic Models of Communication, Coordination, and Cooperation in Economic Relationships, Journal of Economic Perspectives, Vol 30, No 4 : pp 1-12.

9. Al-dabbagh, Issam \& Allawzi, Sulieman (2019) Rethinking scenario planning potential role in strategy making and innovation : A conceptual framework based on examining trends towards scenarios and firm's, Academy of Strategic Management Journal, Vol 18, No 5 : pp 1-14.

10. Hanafizadeh, Payam \& Hashemi, Ali \& Parvin, Esmael Salahi (2009) Robust Strategic Planning Employing Scenario Planning and Fuzzy Inference System, International Journal of Decision Support System Technology, Vol 1, No 3 : pp 21-45.

11. Khosravi, Fatemeh \& Jha-Thakur, Urmila (2018) Managing uncertainties through scenario analysis in strategic environmental assessment, Journal of Environmental Planning and Management : pp 1-23.

12. Liu, Xiaohui Gloria \& Natarajan, Ramachandran (2012) The Effect of Financial Analysts' Strategic Behavior on Analysts' Forecast Dispersion, The accounting revies, Vol 87, No6 : pp 2123-2149.

13. Mirabeau, Laurent \& Maguire, Steve (2014) From autonomous strategic behavior to emergent strategy, Strategic Management Journal, Vol 35 : pp 1202 -1229.

14. Olthof, Tjeert \& Goossens, Frits A. \& Vermande, Marjolijn M. \& Aleva, Elisabeth A. \& Meulen, Matty van der (2011) Bullying as strategic behavior: Relations with desired and acquired dominance in the peer group, Journal of School Psychology, Vol 49 : pp 339-359.

15. Schoemaker, Paul J.H. \& Day, George S. \& Snyder, Scott A. (2013) Integrating organizational networks, weak signals, strategic radars and scenario planning, Technological Forecasting \& Social Change, Vol 80 : pp $815-824$.

16. Shi, Ying \& Lian, Zhaotong (2015) Optimization and strategic behaviorin a passenger-taxi service system, European Journal of Operational Research, Vol 000 : pp 1-9.

17. Volkery, Axel \& Ribeiro, Teresa (2009) Scenario planning in public policy: Understanding use, impacts and the role of institutional context factors, Technological Forecasting \& Social Change, Vol 76 : pp 1198-1207 